\title{
Explorações teóricas para pensar as inter-relações entre educomunicação e comunicação comunitária
}

\author{
Livia Freo Saggin \\ Doutora em Ciências da Comunicação pela Universidade do Vale do Rio dos Sinos (Unisinos), \\ membro do Grupo de Pesquisa Processocom da mesma instituição. \\ Email: liviasaggin@gmail.com
}

Jiani Adriana Bonin

Professora e pesquisadora do Programa de Pós-Graduação em Ciências da Comunicação da Unisinos. E-mail: jianiab@gmail.com

Resumo: $O$ artigo explora e articula os conceitos de educomunicação e de comunicação comunitária na perspectiva das práticas de sujeitos que produzem comunicação, a partir da investigação de propostas de pesquisadores brasileiros e latino-americanos consideradas relevantes para o tratamento destas problemáticas. As reflexões empreendidas têm como horizonte as necessidades concretas de uma pesquisa que investiga os processos educomunicativos desenvolvidos na produção dos jornais Boca de Rua e O Cidadão e seu papel na construção da cidadania comunicativa. As propostas estudadas, trabalhadas em articulação, diálogo e confrontação com dados advindos de explorações empíricas, mostram-se produtivas para entender os processos de educomunicação comunitária desenvolvidos pelos sujeitos comunicantes nos contextos investigados.

Palavras-chave: comunicação comunitária; educomunicação; sujeitos comunicantes; educomunicação comunitária; cidadania comunicativa.
Abstract: The article explores and articulates the concepts of educommunication and community communication in the perspective of the practices of subjects that produce communication, based on the investigation of proposals by Brazilian and Latin American researchers considered relevant for the treatment of these concepts. The reflections undertaken have as horizon the concrete needs of a research that investigates the educommunicative processes developed in the production of the newspapers Boca de Rua and O Cidadão and their role in the construction of communicative citizenship. The proposals, studied in articulation, dialogue and confrontation with data from empirical explorations, are productive to understand the community educommunication processes developed by the communicating subjects in the investigated contexts.

Keywords: community communication; educommunication; communicating subjects; community educommunication; communicative citizenship. 


\section{comunicação \& educação • Ano XXVI • número 1 • jan/jun 2021}

1. MALDONADO, Alberto Efendy. A perspectiva transmetodológica na conjuntura de mudança civilizadora em inícios do século XXI. In: MALDONADO, Alberto Efendy; BONIN, Jiani Adriana; ROSÁRIO, Nísia Martins do (org.). Perspectivas metodológicas em comunicação: novos desafíos na prática investigativa. Salamanca, Espanha: Comunicación Social, 2013. p. 31-57.

2. Impresso trimestral, produzido e vendido por cerca de 40 pessoas em situação de vulnerabilidade social, moradores ou ex-moradores de rua da cidade de Porto Alegre, Rio Grande do Sul. Circula desde agosto de 2000. É mantido pela ONG Agência Livre para Informação, Cidadania e Educação (ALICE), que tem como objetivo desenvolver projetos sociais com a proposta de democratizar e qualificar a informação.

3. O periódico, produzido no conjunto de favelas da Maré, Rio de Janeiro, onde circula, é um projeto da ONG Centro de Estudos e Ações Solidárias da Maré (CEASM). Tem como propósito agir como instrumento de comunicação comunitária entre as $16 \mathrm{fa}$ velas que compõem o complexo da Maré. Fundado em 1999, sua produção noticiosa é realizada por uma equipe de comunicação formada pelos próprios moradores locais.

\section{INTRODUÇÃO}

Entre a virada do século XX e o início do século XXI, a partir da digitalização, o mundo vivencia uma mudança profunda no cenário comunicacional, que entre outras mudanças vem propiciando às pessoas possibilidades renovadas de acompanhar e também de produzir comunicação. O convívio cotidiano com as mídias e com as suas tecnologias digitais modificou a forma como os sujeitos experimentam os processos comunicacionais e o seu potencial transformador ${ }^{1}$.

No cenário latino-americano, propostas e experiências em comunicação comunitária vêm se aproveitando das possibilidades abertas pela digitalização para ampliar suas atividades. Em afinidade com as mudanças nos modos de produzir e de comunicar, desenvolvem-se aprendizados comunicacionais, técnicos, competências relacionadas à comunicação midiática e saberes diversos pelos sujeitos produtores da comunicação.

No âmbito da pesquisa em Comunicação, diversos trabalhos têm se voltado a investigar em profundidade como as tecnologias de comunicação modificam os campos sociais, as interações, as culturas e os modos de ser e de estar no mundo contemporâneo. Outra temática que está ganhando espaço no âmbito científico latino-americano, sobretudo na última década, é a da educomunicação. Geralmente relacionada às novas tecnologias comunicativas e a como se encontram inseridas no campo educacional (formal e não formal), as pesquisas em educomunicação vêm apresentando resultados importantes para a área, principalmente por apontarem como o campo da educação necessita redesenhar suas propostas pedagógicas neste cenário. Essas investigações têm um papel importante para o desenvolvimento de ações concretas, tanto no campo da educação quanto no aprimoramento das tecnologias da informação e comunicação (TICs) inseridas nos processos educacionais.

$\mathrm{Na}$ pesquisa que empreendemos para investigar as práticas dos sujeitos comunicantes na produção dos jornais Boca de Rua ${ }^{2}$ e O Cidadão ${ }^{3}$, reconhecemos a necessidade de levar em conta seu caráter educomunicativo, vinculado à conquista e ao exercício da cidadania dos sujeitos envolvidos. A atuação constante, crítica e constitutiva dos sujeitos produtores de comunicação é tangível e central dentro dos contextos observados em nossas explorações empíricas e nos leva a concebê-los como partícipes dos processos comunicativos, bem como a levar em conta o complexo de mediações constituintes desses processos.

Em alinhamento a essa investigação, a proposta deste artigo é explorar teoricamente perspectivas para se pensar nas inter-relações entre educomunicação e comunicação comunitária e na noção de sujeitos comunicantes. Metodologicamente, a discussão se nutre de uma pesquisa teórica de propostas de pesquisadores brasileiros e latino-americanos, escolhidas pela fertilidade e relevância para o tratamento destas problemáticas. As propostas foram confrontadas com dados advindos de explorações empíricas realizadas nos contextos investigados para fomentar sua problematização e reconstrução de maneira alinhada às especificidades da pesquisa em desenvolvimento. 


\section{DIÁLOGOS POSSÍVEIS ENTRE COMUNICAÇÃO COMUNITÁRIA E EDUCOMUNICAÇÃO}

Contemporaneamente, em nosso ambiente sociocomunicacional, atravessado pelos processos de midiatização e de digitalização, as dimensões socioculturais, econômicas, ideológicas, políticas, educacionais e cidadãs encontram-se em transformação. A presença mais ampla das tecnologias comunicacionais dentro dos processos educativos nas práticas sociais, coletivas, criativas e políticas é evidente e configura um processo sem volta.

Diante desse contexto, como argumenta Baccega, os pressupostos e as práticas do campo da educomunicação assumem como objetivos centrais o reconhecimento das variadas construções de mundo ofertadas pelos meios de comunicação; a melhoria das capacidades expressivas, de relacionamento em comunidade e de formação de identidades; o incentivo a processos de ensino-aprendizagem por meio da utilização e da apropriação inventiva, criativa e comunitária dos meios de comunicação; e a democratização do acesso dos cidadãos às práticas de produção e circulação da informação ${ }^{4}$.

Não longe destes objetivos, a comunicação comunitária caminha para efetivar o exercício do direito à comunicação, condição que amplia os horizontes da garantia de outros direitos, principalmente, para aqueles sujeitos e comunidades que se encontram às margens dos grandes centros econômicos, políticos e midiáticos da sociedade $^{5}$. A concentração midiática e a centralização de discursos e pontos de vista sobre a sociedade a partir de suas lógicas têm gerado exclusão e invisibilização de grupos perante a opinião pública, que não raras vezes dependem quase que exclusivamente da experimentação junto ao campo comunicacional para fazer valer suas pautas frente às lutas políticas que perpassam suas existências coletivas ${ }^{6}$.

Atenta às intersecções entre as áreas da comunicação e da educação, a compreensão freireana da comunicação destaca que ela é uma característica essencial da humanidade; que, ao constituir ontologicamente a natureza humana, se fundamenta na dialogicidade como "compromisso político com a mudança revolucionária na perspectiva dos oprimidos"7; que se configura como relação social contextualizada e histórica, sendo pensada como ação cultural para a liberdade; que se constitui como relação dialógica instaurada no contexto de interesses distintos das classes sociais ${ }^{8}$. A junção das potencialidades comunicacionais às educacionais, nesta perspectiva, reconfigura um outro campo de ação e investigação, que é o educomunicacional.

Paulo Freire descortina a estrutura dialógica da comunicação ao elaborar uma "pedagogia da palavra e ação" ${ }^{9}$. Como apontam Brandalise e Assencio, na intersecção entre comunicação e educação coexiste a possibilidade dos sujeitos fazerem uso de palavras originalmente próprias dos dominantes para "dizer coisas novas que ilustram seus anseios e suas lutas" ${ }^{10}$. Ou seja, reside nessa ideia uma pragmática que converge em uma proposta de ação e de expressão, concebendo que, por meio da fala, da expressão escrita, da utilização refletida dos meios de comunicação e de suas tecnologias, agimos no mundo.
4. BACCEGA, Maria Aparecida. Comunicação/ educação e a construção de nova variável histórica. Comunicação \& Educação, São Paulo, v. 4, n. 3. p. 1928, set./dez., 2009. DOI: 10.11606/issn.2316-9125. v14i3p19-28.

5. PERUZZO, Cicilia Maria Krohling. Direito à comunicação comunitária, participação popular e cidadania. Revista Latinoamericana de Ciencias de la Comunicación, São Paulo, n. 3, p. 18-53, 2005. Disponível em: https://www.alaic.org/ revista/index.php/alaic/article/view/145/166. Acesso em: 8 maio 2019.

6. PAIVA, Jane. Tramando concepções e sentidos para redizer o direito à educação de jovens e adultos. Revista Brasileira de Educação, Rio de Janeiro, v. 11, n. 33, p. 519-566, set./dez. 2006. Disponível em: http://www. scielo.br/pdf/rbedu/v11n33/ a12v1133.pdf. Acesso em: 10 jul. 2019.

7. FIGARO, Roseli. Paulo Freire, comunicação e democracia. Comunicação e Educação, São Paulo, v. 20, n. 1, p. 7-15, 2015. DOI: https://doi.org/10.11606/ issn.2316-9125.v20i1p7-15. p.10

8. Ibidem.

9. BRANDALISE, Roberta; ASSENCIO, Sandro. Contra a barbárie da incomunicação e pela construção de uma sociedade educativa. Matrizes, São Paulo, v. 8, n. 2, p. 313317, jul./dez., 2014. DOI: 10.11606/issn.1982-8160. v8i2p313-317. p.314.

10. Ibidem, p. 314. 


\section{comunicação \& educação • Ano XXVI • número 1 • jan/jun 2021}

11. BACCEGA, op. cit., p. 27.

12. CITELLI, Adilson. Comunicação e educação: implicações contemporâneas. Comunicação \& Educação São Paulo, v. 15, n. 2, p. 13 27, maio/ago. 2010. DOl: 10.11606/issn.2316-9125 v15i2p13-27.

13. PONTE, Cristina; CONTRERAS-PULIDO, Paloma Presente y futuro de la alfabetización mediática en Europa: el caso español y portugués. Revista Chasqui, Quito, n. 124, p. 19-25 dez. 2013. DOI: 10.16921/ chasqui.v0i124.14.

14. HUERGO, Jorge A. Comunicación/educación: ámbitos, prácticas, perspectivas. La Plata: Ediciones de Periodismo y Comunicación, 2001.

15. PERUZZO, op. cit., 2005; PERUZZO, Cicilia Maria Krohling. Comunicação nos movimentos populares. Petrópolis: Vozes, 1998.
Os processos educomunicativos, como argumenta Baccega, dotam os sujeitos de competências para "construir novos modos de atuação na mídia e no mundo"11. Os novos desafios postos à educação, na compreensão de Citelli, passam pelo atravessamento dos modos como informação e conhecimento são "elaborados, distribuídos e socialmente intercambiados"12. Como proposto no pensamento freireano, o encontro dos campos da comunicação e da educação pode representar, através de dinâmicas fundadas no diálogo, o surgimento de processos educativos e a potencialização dos conhecimentos a partir de mediadores técnicos e de dispositivos comunicacionais apreendidos e reinventados socialmente.

Retomando historicamente abordagens educomunicacionais em distintos contextos, Ponte e Contreras-Pulido ${ }^{13}$ refletem que a orientação modernizadora tem estado presente em diferentes contextos governamentais, a partir dos quais a mirada difusora de TICs vem sendo pensada como forma de inovação, integração e consequente desenvolvimento social. Ao detalharem semelhanças e disparidades em diferentes países europeus, sinalizam um movimento esvaziado que se assenta em uma visão instrumentalista e que favorece apenas as empresas fornecedoras do setor. Atentando para os levantamentos realizados pelas autoras, visualizamos a natureza tecnicista de tais abordagens e refletimos que a mera utilização das tecnologias da comunicação pode reproduzir e fortalecer a educação tecnológica, deixando de se aproveitar as possibilidades de desenvolvimento de conhecimentos socioculturais e críticos pelos sujeitos.

Essa perspectiva dialoga com a de Huergo $^{14}$ e nos provoca a pensar se as TICs, colocadas como alternativa à crise educativa avistada contemporaneamente, não estão se transformando em novos "livros", mantendo intactos os regimes tecnocráticos e disciplinares vinculados à concepção transmissional do conhecimento. Deste modo, abordagens pedagógicas voltadas apenas aos usos das tecnologias comunicacionais não seriam suficientes para romper com as dificuldades e necessidades de adaptação dos processos de ensino-aprendizagem aos contextos multimidiatizados e às características dos sujeitos comunicantes envolvidos neles. Compreendemos que a constituição educomunicativa dentro dos contextos socioculturais e políticos latino-americanos necessita ser fundamentada em processos apropriativos das tecnologias ofertadas pelos sujeitos, de maneira a transformá-las em elementos socioculturais voltados à reflexão crítica da realidade, à transformação social e à conquista da cidadania.

Ao propormos possibilidades de aproximação entre os conceitos de educomunicação e de comunicação comunitária, levamos em conta as contribuições de Peruzzo $^{15}$ para pensar que a participação popular junto aos processos comunicacionais está subordinada à própria estrutura dos meios de comunicação de massa, que, através de sua organização em escalas burocráticas de poder, impede que ela possa ser organizada de modo representativo dentro de um meio de comunicação já constituído. Dessa forma, uma estratégia com vistas à maior participação popular nos meios de comunicação, tanto nos que se voltam às pequenas audiências quanto nos de audiência massiva, é a democratização que, em nosso entendimento, é viável por meio da inserção de processos educomunicativos que estimulem e promovam 
capacidades, criatividades, subjetividades, valores comunitários, cidadãos e críticos nos sujeitos partícipes, tendo como horizonte a transformação social. Esses processos educomunicativos são caracterizados pela aprendizagem comunicacional e midiática voltada, sobretudo, à leitura, ao uso e à produção crítica e transformadora junto às mídias comunitárias.

Observando os processos de produção comunicacional nos cenários empíricos de nossa pesquisa, notamos a presença de ações que podem ser pensadas como práticas de comunicação comunitária. Essas ações baseiam-se em processualidades que envolvem: a participação efetiva dos sujeitos nas comunidades nas quais se dão as experiências de comunicação; a presença de processos de decisão editorial e produtiva mais horizontais; a escolha de temáticas ligadas às realidades sociais do entorno comunitário; a ênfase no tom denunciativo e reivindicatório nas produções comunicacionais e midiáticas; a presença de marcas das mediações sociais, culturais, econômicas e políticas nos produtos produzidos; a busca por uma estética narrativa comunicacional própria, entre outras. Essas processualidades instauram a democratização da comunicação desde o acesso até a produção dos meios de comunicação. Visualizamos que na base desse processo encontra-se o que temos chamado de território comunitário.

A compreensão de território comunitário que estamos desenvolvendo, derivada em parte do conceito de Milton Santos ${ }^{16}$, concebe-o como lugar onde as relações horizontais são potencializadas pelo acontecer solidário. As solidariedades plurais coexistentes geram valores de distintas ordens: culturais, sociais, comunicacionais, antropológicas, econômicas etc. Por isso, entendemos o território comunitário como um universo de resistência da sociedade civil à exclusão e às desigualdades, como um lócus onde as relações dos sujeitos e das comunidades são potencializadas pelo acontecer solidário, fruto da ação política, social e também educomunicacional e comunitária. As horizontalidades geridas dentro deste local podem permitir uma espécie de luta comunicacional e territorial frente aos processos globais excludentes, o que viabiliza a restauração da dignidade humana em seus lugares de existência cotidiana.

Nesse sentido, tanto os moradores em situação de rua produtores do jornal Boca de Rua quanto os do complexo de favelas da Maré que produzem O Cidadão são compreendidos por nós como sujeitos educomunicantes comunitários, visto que suas ações comunicacionais são fruto de um significativo aprendizado junto às mídias, originado da experiência cotidiana e também do processo educativo vivenciado por eles nos cenários de comunicação comunitária. Nos casos explorados, vislumbramos que o aprendizado do uso das mídias ultrapassa o nível tecnicista, já que se realiza com base num exercício reflexivo e crítico sobre as realidades vividas pelos sujeitos, motivado por circunstâncias e por lutas que alimentam o horizonte comunitário. A comunicação comunitária se configura, nestes dois horizontes concretos, como espaço de aprendizado, de visibilização de lutas e de exercício cidadão.

16. SANTOS, Milton. Técnica, espaço, tempo: globalização e meio técnico-científico informacional. São Paulo: Hucitec, 1994. 


\section{PERSPECTIVAS EDUCOMUNICATIVAS CRÍTICAS}

Mais do que nunca, iniciativas de aproveitamento dos saberes técnicos, criativos e colaborativos proporcionados pela comunicação na experiência cotidiana dos sujeitos juntos às redes de comunicação precisam ser efetivadas. Nesta via, nossa perspectiva se alinha a abordagens que reconhecem, nas tecnologias comunicacionais digitais postas a serviço da educação, a possibilidades de reincorporação do sentido dialógico do processo educacional, reiterando a necessidade da escuta e da participação dos sujeitos aprendizes. Esses são pressupostos centrais das propostas pedagógicas de Freire, nos quais a dialogia é entendida como elemento basilar, devendo ser potencializada a partir da vinculação entre os campos comunicacional e educacional, compreendidos, contemporaneamente, como constitutivos de um processo educomunicacional ${ }^{17}$.

Pressupostos sobre os processos educomunicativos associados às problemáticas latino-americanas foram desenvolvidos por pensadores críticos do continente, tais como Simón Rodríguez, pedagogo venezuelano que viveu no século XVIII e produziu ideias para repensar propostas pedagógicas desde as matrizes culturais, sociais e políticas próprias da América Latina, partindo de um prisma decolonial e transformador; Mario Kaplún, reconhecido pesquisador argentino que viveu a maior parte da vida no Uruguai, cujas propostas têm como base a recuperação do elo dialógico nos processos comunicacionais, pensando-os como eixos importantes para a transformação política e social latino-americana; e Paulo Freire, cuja vida e obra oferecem à pesquisa em educação e em comunicação bases férteis para pensar o diálogo, a interação e o aproveitamento dos contextos como elementos inerentes e fundamentais para a transformação a partir da educação e da comunicação.

Na obra de Rodríguez ${ }^{18}$, cujas ideias foram relevantes para a produção de um pensamento epistêmico latino-americano e para uma educação condizente com as necessidades de nossos países, avistamos a preocupação em pensar a educação

17. FREIRE, Paulo. Ação cultural para a liberdade e outros escritos. 5. ed. Rio de Janeiro: Paze Terra, 1981; Idem. Pedagogia do oprimido.17. ed. São Paulo: Paz e Terra, 1987; Idem. Pedagogia da autonomia: saberes necessários a prática educativa. 12. ed. São Paulo: Paz e Terra, 1999.

18. RODRÍGUEZ, Simón. Extracto sucinto de mi obra sobre la educación republicana. Revista Historia de la Educación Latinoamericana, Boyacá, n. 9, p. $105-$ 134, 2007. Disponível em: https://www.redalyc.org/ articulo.oa?id=869/869009. Acesso em: 22 abr. 2019. Idem. O inventamos o erramos. Caracas: Monte Ávila Editores Latinoamericana CA, 2008. como um direito básico de todos os sujeitos a ser usufruído de maneira democrática e vinculada às vivências cotidianas das culturas populares, de modo a possibilitar a libertação da subjugação epistêmica por meio da construção de conhecimentos e da expressão cidadã. No seu pensamento, a educação passa a ser vista para além da mera elitização intelectual dos sujeitos. Os processos educativos norteiam-se pela busca da horizontalização das posições socioculturais e econômicas e pela modificação não somente dos saberes individuais mas também dos coletivos, de modo a constituir uma renovada transformação, mais ampla e configurada pela reforma política latino-americana. A própria história dos sujeitos precisa ser reconsiderada dentro das dinâmicas educativas.

Esses preceitos estão também presentes nas obras de Freire. O pensamento destes autores é complementar em relação às suas dinâmicas interpretativas da necessidade de construção de uma episteme educomunicacional latino-americana. Em Freire, encontramos a perspectiva do diálogo como dimensão central que, junto à concepção de autonomia, propicia o desenvolvimento de capacidades de entendimento e de ação sobre o mundo. 
Kaplún ${ }^{19}$ também contribui com essa reflexão com a sua crítica à cópia de modelos educacionais desvinculados das características e problemáticas latino-americanas. Compartilhamos com ele a ideia de que "conhecer é comunicar", na medida em que a presença da comunicação dentro dos processos educativos se mostra fundamental para a construção do conhecimento e para a formação de consciências críticas, reflexivas e preocupadas com os contextos socioculturais e políticos, tal como propõem Rodríguez e Freire.

Quando analisamos as perspectivas destes autores, enxergamos problematizações que extrapolam a esfera educacional. Ao considerarmos a emergência e penetração das áreas comunicacionais/midiáticas como vetores cruciais dentro das mais diversas experiências cotidianas dos sujeitos contemporâneos, argumentamos sobre a necessidade de repensar esses domínios como educomunicacionais. Compreendemos ser possível aproximar as propostas destes autores das desenvolvidas por pesquisadores que avistam na educomunicação possibilidades de formação de sentidos sociais renovados nos sujeitos.

Em relação a isso, Martín Barbero ${ }^{20}$, Baccega $^{21}$, Soares $^{22}$, Alves $^{23}$ e Huergo $^{24}$ debatem, na essência de suas obras, sobre as possibilidades educativas que se abrem quando as produções midiáticas são aproximadas das realidades socioculturais, econômicas e políticas em que vivem os sujeitos e como são observáveis movimentos reflexivos, críticos e reivindicatórios entrelaçados a essas práticas. No âmago desse entrelaçamento afloram processos que permitem, inclusive, a construção de novos modos de ser e de agir sobre o mundo e sobre a mídia.

No que tange à pesquisa que desenvolvemos, procuramos descortinar como os processos educomunicativos realizados nos âmbitos comunitários estudados se vinculam à conquista e ao exercício da cidadania. Concebemos que, ao demarcar presença num espaço público antes ocupado somente pelas mídias hegemônicas, através da produção dos jornais Boca de Rua e O Cidadão, os sujeitos passam a dar visibilidade e a buscar o reconhecimento social de problemáticas silenciadas e invisibilizadas por um âmbito tradicional da comunicação que se comporta de maneira excludente. Na ocupação de espaços comunicacionais, mesmo que delimitados e contextualmente situados, os sujeitos potencializam vozes e, a partir disso, dão início a um processo mais amplo e complexo para a conquista de uma condição cidadã através da comunicação.

Torna-se evidente, por meio de uma análise transversal sobre pesquisas que debatem este escopo, que o acesso aos meios de comunicação não alcançou de maneira uniforme todos os níveis da sociedade contemporânea. Sobre isso versam parte dos argumentos de $\operatorname{Santos}^{25}$ quando defende a imprescindibilidade da emergência de uma nova cultura política que seria edificável somente a partir uma globalização contra-hegemônica e que afetaria, inclusive, as esferas midiáticas.

Diante dos cenários dispostos às experiências em comunicação comunitária, sobretudo aquelas analisadas em nossa pesquisa, é necessário levar em conta que grandes parcelas da sociedade continuam à margem do acesso à produção e à representação midiática. Consideramos que as relações de mercado, entrelaçadas com os interesses de setores hegemônicos, prevalecem sobre as instituições e os
19. KAPLÚN, Mário. El comunicador popular. Quito: Ciespal, 1985; Idem. A la educación por la comunicación: la práctica de la comunicación educativa. Quito: Ciespal, 2001.

20. MARTÍN-BARBERO, Jesús. Tecnicidades, identidades, alteridades: mudanças e opacidades da comunicação no novo século. In: MỎRAES, Dênis de (org.) Sociedade Midiatizada. Rio de Janeiro: Mauad X 2006. p. 51-79.

21. BACCEGA, op. cit.

22. SOARES, Ismar de Oliveira. Educomunicação o conceito, o profissional, a aplicação: contribuições para a reforma do ensino médio. São Paulo: Paulinas, 2011.

23. ALVES, Patrícia Horta Educom.rádio: uma política pública em educomunicação. 2007. 207 f. Tese (Doutorado em Ciências da Comunicação) - Escola de Comunicações e Artes, Universidade de São Paulo, São Paulo, 2007.

24. HUERGO, op. cit.

25. SANTOS, Boaventura de Souza. A gramática do tempo: para uma nova cultura política. Porto: Edições Afrontamento, 2006. 
sujeitos das classes populares, forçando-os, muitas vezes, a uma invisibilização midiática, sem que possam manifestar, na esfera pública, reinvindicações que emergem de suas realidades cotidianas.

Numa mirada mais ampla, sobretudo para produções recentes do campo da educomunicação, preocupamo-nos ao encontrar um reducionismo das problemáticas que não vêm mais respondendo às grandes questões propostas desde uma abordagem educomunicativa crítica iniciada pelos movimentos sociocomunicacionais e comunitários latino-americanos.

\section{PENSANDO OS SUJEITOS EDUCOMUNICANTES COMUNITÁRIOS}

Para pensar as produções comunicacionais efetivadas pelos sujeitos comunicantes investigados em nossa pesquisa, precisamos problematizá-los em termos dos atravessamentos da midiatização, que são constitutivos das suas competências e culturas, assim como das mediações socioculturais e de contexto que configuram estes usos e apropriações ${ }^{26}$. Concebemos os agentes da comunicação como sujeitos pensantes, reflexivos, capazes de discernir sobre aquilo que consomem e produzem midiaticamente, apropriando-se, ressignificando e recirculando os bens simbólicos dentro de esferas que conformam suas cotidianidades. As explorações empíricas realizadas em nossa pesquisa têm demonstrado que a noção de sujeito comunicante $^{27}$ se aproxima das experiências educomunicativas e comunitárias avistadas nos cenários investigados. Constatamos isso tanto nos produtos comunicacionais e midiáticos quanto nas processualidades produtivas destes espaços, ao visualizarmos a existência de sujeitos que conquistam a possibilidade de expressar suas subjetividades multicontextuais pela comunicação, em processos educomunicativos e comunitários, de maneira reflexiva, crítica e transformadora. As reflexões que esses sujeitos elaboram sobre seus universos multifacetados dão a entender que eles não se assujeitam diante das desigualdades político-econômicas-sociais, produzindo narrativas contestatórias que disputam sentidos e legitimidade frente a espaços hegemônicos da comunicação midiatizada. Suas participações ativas nos processos educomunicativos e comunicacionais ampliam horizontes de

26. MARTÍN-BARBERO, Jesús. Dos meios às mediações: comunicação, cultura e hegemonia. Rio de Janeiro: Editora da UFRJ, 2009.

27. MALDONADO, Alberto Efendy. Perspectivas transmetodológicas na pesquisa de sujeitos comunicantes em processos de receptividade comunicativa. In: MALDONADO, Alberto Efendy (org.). Panorâmica da investigação em comunicação no Brasil. Salamanca, Espanha: Comunicación Social Ediciones y Publicaciones, 2014. p. 17-40. aprendizagem e de ação comunitária vinculadas às lutas por cidadania nos âmbitos educativo, comunicacional e sociocultural.

As observações realizadas nos dois contextos demonstram, ainda, a pertinência de levar em conta as proposições de Martín-Barbero relativas aos atravessamentos das mediações que configuram e reforçam as atividades comunicacionais destes sujeitos. Esse exercício exige pensá-los como sujeitos multifacetados, plurais e complexos; detentores de competências culturais, midiáticas e comunicativas; e situados em entornos educativos, sociais, socioeconômicos, culturais, religiosos, além de outras dimensões.

Constatamos que os sujeitos, a partir de experiências educomunicacionais e comunitárias em que estão envolvidos, alcançam saberes para a expressão de 
suas formações subjetivas e epistêmicas através da comunicação midiática. Essa movimentação apropriativa sobre os modos de fazer a comunicação não se dá em uma esfera instrumental. Assim, vemos que as características educomunicacionais e comunitárias, quando trabalhadas em perspectiva crítica, tendem a oferecer aos sujeitos potencialidades para uma atuação reflexiva, não assujeitada perante matrizes hegemônicas voltadas à manutenção das desigualdades e à opressão.

As narrativas produzidas por esses sujeitos possuem, ainda, outra característica marcante: são contestatórias e disputam sentidos e legitimidade com os espaços hegemônicos da comunicação midiatizada. Embora se considere as desproporcionalidades em termos estruturais e de forças organizativas do poder (sobretudo político e econômico), a atuação dos sujeitos frente a espaços educomunicacionais-comunitários demonstra a potência das matrizes comunitárias voltadas ao alargamento da cidadania em suas diferentes expressões (comunicacional, educacional, política, científica, cultural, entre outras). Essa constatação nos permite pensar na existência de sujeitos educomunicantes comunitários para dar conta destas realidades em observação na pesquisa.

Ainda como eixo teórico-epistêmico transversal à problemática investigada está a cultura. Em nossa perspectiva, ela é componente essencial dentro dos projetos e processos de transformação pela democratização. Entre eles está a transformação pela comunicação, compreendida como "espaço não só de manipulação, mas também de conflito, e (da) possibilidade então de transformar em meios de libertação as diferentes expressões ou práticas culturais" ${ }^{28}$. Concebendo a conjuntura comunicacional contemporânea e as práticas dos sujeitos comunicantes articuladas a diversos fatores, como a própria abertura aos processos de produção possibilitada pela digitalização, avistamos a imprescindibilidade de problematizar as culturas como elementos vivos e centrais para a compreensão dos fenômenos comunicacionais/midiáticos contemporâneos.

Finalmente, consideramos que as perspectivas delineadas permitem pensar que os processos educomunicacionais podem promover a constituição da cidadania dos sujeitos e de suas comunidades, ao oportunizar a publicização e a existência pública de suas demandas, possibilitando que sejam representados dentro das esferas públicas midiatizadas. Como propõe Dagnino ${ }^{29}$, a cidadania é construída e efetivada a partir de práticas concretas e de lutas dos sujeitos, como o direito a requerer direitos junto à esfera pública e midiática. Guareschi aporta a essa reflexão ao propor que é na "prática de falar, de se comunicar, que o ser humano se expressa, se exterioriza, como verdadeiro criador e agente da história" ${ }^{30}$ Entendemos, em diálogo com Cortina ${ }^{31}$, que um conceito de cidadania contemporâneo necessita considerar tanto dimensões vinculadas às esferas dos sujeitos, concebendo suas múltiplas heterogeneidades (culturais, sociais, econômicas, políticas, psicológicas etc.) quanto à forma como interagem entre si e com as suas comunidades.

Nessa discussão, é importante destacar, como argumenta Peruzzo ${ }^{32}$, que a comunicação é uma dimensão fundamental para o exercício da cidadania de todos os sujeitos. Aos envolvidos nos processos da educomunicação e da comunicação comunitária, a efetiva participação, a construção e o aprendizado com e para
28. MARTÍN-BARBERO, op cit., 2009, p. 44

29. DAGNINO, Evelina. Os movimentos sociais e a emergência de uma nova noção de cidadania. In: DAGNINO, Evelina (org.) Anos 90: política e sociedade no Brasil. São Paulo: Brasiliense, 1994. p. xx-xx. Disponível em: http://www. portalpbh.pbh.gov.br/pbh/ ecp/files.do?evento=download\&ur|ArqPIc=os_movimentos_sociais_e_a_emergencia_de_uma_nova_nocao_de_ci.pdf. Acesso em: 3 mar. 2016.

30. GUARESCHI, Pedrinho. Mídia e cidadania. Conexão - Comunicação e Cultura, Caxias do Sul, v. 5 n. 9, p. 27-40, jan./jun. 2006. Disponível em: http://www. ucs.br/etc/revistas/index. php/conexao/article/viewFile/\%20202/193. Acesso em: 2 jun. 2019

31. CORTINA, Adela. Cidadãos do mundo: para uma teoria da cidadania. São Paulo: Loyola, 2005.

32. PERUZZO, Cicilia Maria Krohling. A comunicação no desenvolvimento comunitário e local, comcibercultur@.In: ENCONTRO ANUAL DA COMPÓS, 21. 2012, Juiz de Fora. Anais eletrônicos... Juiz de Fora, 2012. Disponível em: http:// www.compos.org.br/data/ biblioteca_1803.pdf. Acesso em: 19 abr. 2019. 
as mídias possibilita a criação de laços de pertença com suas comunidades; gera afetações dentro dos cenários constitutivos dos sujeitos; e faz com que se sintam partícipes no interior das dinâmicas decisórias de suas comunidades, configurando o que se tem compreendido por movimentos de construção e exercício da cidadania comunicativa.

As possibilidades de expressão e de ampliação das vozes periféricas e comunitárias em relação às suas demandas, através das produções educomunicacionais comunitárias, são entendidas como uma das formas de constituição de cidadania, defendida aqui como cidadania comunicativa.

Compreendemos que a cidadania e o exercício dela são aprendizagens que não se dão instantaneamente apenas pelo cumprimento de regras e, até mesmo, por legislações oriundas de poderes governamentais. Essa conquista se dá pela vivência, pelo compartilhamento e pelo aprendizado cidadão ${ }^{33}$. Nossas observações exploratórias têm sinalizado que estas práticas educomunicativas, alinhadas a processos de comunicação comunitária constituídos no âmago dos contextos dos sujeitos, têm possibilitado o fortalecimento de suas lutas, impulsionando capacidades e competências dialógicas, criativas, expressivas e autônomas dentro de seus núcleos tangíveis e, também, nos espaços de comunicação nos quais existem como sujeitos educomunicantes comunitários.

\section{REFERÊNCIAS BIBLIOGRÁFICAS}

ALVES, Patrícia Horta. Educom.rádio: uma política pública em educomunicação. 2007. Tese (Doutorado em Ciências da Comunicação) - Escola de Comunicações e Artes, Universidade de São Paulo, São Paulo, 2007.

BACCEGA, Maria Aparecida. Comunicação/educação e a construção de nova variável histórica. Comunicação \& Educação, São Paulo, v. 4, n. 3. p. 19-28, 2009. DOI: https://doi.org.10.11606/issn.2316-9125.v14i3p19-28.

BRANDALISE, Roberta; ASSENCIO, Sandro. Contra a barbárie da incomunicação e pela construção de uma sociedade educativa. MATRIZes, São Paulo, v. 8, n. 2, p. 313-317, 2014. DOI: https://doi.org/10.11606/issn.1982-8160.v8i2p313-317.

CITELLI, Adilson. Comunicação e educação: implicações contemporâneas. Comunicação \& Educação, São Paulo, v. 15, n. 2, p. 13-27, 2010. DOI: https:/ / doi.org/10.11606/issn.2316-9125.v15i2p13-27.

CORTINA, Adela. Cidadãos do mundo: para uma teoria da cidadania. São Paulo: Loyola, 2005.

DAGNINO, Evelina. Os movimentos sociais e a emergência de uma nova noção 
FIGARO, Roseli. Paulo Freire, comunicação e democracia. Comunicação e Educação, São Paulo, v. 20, n. 1, p. 7-15, 2015. DOI: https://doi.org/10.11606/ issn.2316-9125.v20i1p7-15.

FREIRE, Paulo. Ação cultural para a liberdade e outros escritos. 5. ed. Rio de Janeiro: Paz e Terra, 1981.

FREIRE, Paulo. Pedagogia do oprimido.17. ed. Rio de Janeiro: Paz e Terra, 1987.

FREIRE, Paulo. Pedagogia da autonomia: saberes necessários a prática educativa. 12. ed. Rio de Janeiro: Paz e Terra, 1999.

GUARESCHI, Pedrinho. Mídia e cidadania. Conexão - Comunicação e Cultura, Caxias do Sul, v. 5, n. 9, p. 27-40, 2006. Disponível em: http://www.ucs.br/etc/ revistas/index.php/conexao/article/viewFile/\%20202/193. Acesso em: 2jun. 2019. HUERGO, Jorge A. Comunicación/educación: ámbitos, prácticas, perspectivas. La Plata: Ediciones de Periodismo y Comunicación, 2001.

KAPLÚN, Mario. El comunicador popular. Quito: Ciespal, 1985.

KAPLÚN, Mario. A la educación por la comunicación: la práctica de la comunicación educativa. Quito: Ciespal, 2001.

MALDONADO, Alberto Efendy. A perspectiva transmetodológica na conjuntura de mudança civilizadora em inícios do século XXI. In: MALDONADO, Alberto Efendy; BONIN, Jiani Adriana; ROSÁRIO, Nísia Martins do (org.). Perspectivas metodológicas em comunicação: novos desafíos na prática investigativa. Salamanca, Espanha: Comunicación Social Ediciones y Publicaciones, 2013. p. 31-57.

MALDONADO, Alberto Efendy. Perspectivas transmetodológicas na pesquisa de sujeitos comunicantes em processos de receptividade comunicativa. In: MALDONADO, Alberto Efendy (org.). Panorâmica da investigação em comunicação no Brasil. Salamanca, Espanha: Comunicación Social Ediciones y Publicaciones, 2014. p. 17-40.

MARTÍN-BARBERO, Jesús. Tecnicidades, identidades, alteridades: mudanças e opacidades da comunicação no novo século. In: MORAES, Dênis de (org.). Sociedade Midiatizada. Rio de Janeiro: Mauad X, 2006. p. 51-79.

MARTÍN-BARBERO, Jesús. Dos meios às mediações: comunicação, cultura e hegemonia. Rio de Janeiro: Editora da UFRJ, 2009.

PAIVA, Jane. Tramando concepções e sentidos para redizer o direito à educação de jovens e adultos. Revista Brasileira de Educação, Rio de Janeiro, v. 11, n. 33, p. 519-566, 2006.

PERUZZO, Cicilia Maria Krohling. Comunicação nos movimentos populares. Petrópolis: Vozes, 1998. 
PERUZZO, Cicilia Maria Krohling. Direito à comunicação comunitária, participação popular e cidadania. Revista Latinoamericana de Ciencias de la Comunicación, São Paulo, n. 3, p. 18-53, 2005.

PERUZZO, Cicilia Maria Krohling. A comunicação no desenvolvimento comunitário e local, comcibercultur@. In: ENCONTRO ANUAL DA COMPÓS, 21. 2012, Juiz de Fora. Anais eletrônicos [...] Juiz de Fora, 2012. Disponível em: http:/ /www.compos.org.br/data/biblioteca_1803.pdf. Acesso em: 19 abr. 2019.

PONTE, Cristina; CONTRERAS-PULIDO, Paloma. Presente y futuro de la alfabetización mediática en Europa: el caso español y portugués. Revista Chasqui, Quito, n. 124, p. 19-25, dez. 2013. DOI: 10.16921/chasqui.v0i124.14. RODRÍGUEZ, Simón. Extracto sucinto de mi obra sobre la educación republicana. Revista Historia de la Educación Latinoamericana, Boyacá, n. 9, p. 105-134, 2007. Disponível em: https://biblat.unam.mx/hevila/ Revistahistoriadelaeducacionlatinoamericana/2007/vol9/4.pdf. Acesso em: 22 abr. 2019.

RODRÍGUEZ, Simón. O inventamos o erramos. Caracas: Monte Ávila Editores Latinoamericana CA, 2008.

SANTOS, Boaventura de Sousa. A gramática do tempo: para uma nova cultura política. 2. ed. São Paulo: Cortez, 2006.

SANTOS, Milton. Técnica, espaço, tempo: globalização e meio técnicocientífico informacional. São Paulo: Hucitec, 1994.

SOARES, Ismar de Oliveira. Educomunicação: o conceito, o profissional, a aplicação: contribuições para a reforma do ensino médio. São Paulo: Paulinas, 2011. 